\title{
High-altitude water budgets: ecological and hydrological forest research in view of landscape modelling
}

\author{
R. Matyssek - C. Bernhofer $\cdot$ B. Huwe
}

Published online: 24 October 2009

(C) Springer-Verlag 2009

Modelling of water relations at the landscape and regional scale has largely suffered from simplifications hardly validated or examined in their consequences for interpreting and quantifying interrelationships between system ecology and hydrology. On such grounds, the overall aim of the studies gathered under the special theme of this issue of "European Journal for Forest Research" was to foster the process-related ecological and hydrological basis of ecosystem and landscape modelling with particular attention to the spatio-temporal variation in water fluxes. Research objects were mountainous forests with emphasis on the Northern Alps of Central Europe, including comparisons with colline and subalpine scenarios (e.g. Matyssek et al. 2009) and with the specificities of high-altitude forests in the tropics (Engelhardt et al. 2009).

Regarding the Northern Alps, knowledge on the water demand of spruce/beech forests, in particular, with respect to mature stands, was rather limited, being in distinct

This editorial relates to the following four articles. They report research that was conducted in the context of the DFG-funded umbrella project 'Methodologies in linking hydrological and biological processes at the landscape level-a contribution to IGBP/ BAHC Research in Germany' (DFG: Deutsche Forschungsgemeinschaft, German Research Foundation).

R. Matyssek ( $\square)$

Ecophysiology of Plants, Technische Universität München/ Weihenstephan, Am Hochanger 13, 85354 Freising, Germany e-mail: matyssek@wzw.tum.de

\section{Bernhofer}

Meteorology, Technische Universität Dresden, Pienner Str. 23, 01737 Tharandt, Germany

B. Huwe

Soil Physics Group, University of Bayreuth, Universitätsstr. 30, 95440 Bayreuth, Germany contrast with the ample evidence available on low-altitude forests (e.g. Köstner et al. 1998; Köstner 2001). Such latter evidence can hardly be extrapolated, however, to mountainous scenarios, given the specific constraints at high altitude imposed by climate and topography, their effects on stand structure and canopy exposure and the ultimately resulting consequences for system hydrology. Research demand is also given in more general terms in that thorough process understanding requires the analysis of extremes in ecological gradients. In fact, mountainous forests represent such extremes - the more so as underlying mechanisms of high-altitude hydrology still require clarification.

Emphasis on mountainous forests is also timely in view of their increasing sensitivity to environmental impact as approaching the timberline ecotone (Wieser and Tausz 2007; Körner 2003). This tendency has become increasingly relevant in relation to climate change with nonclarified but probable effects on high-altitude ecosystems, and to efforts in forestry of re-establishing mixed stands (Dertz 1996), including at high elevation sites. In the case of the Northern Alps, re-structuring at least comprises broadleaf European beech (Fagus sylvatica) and coniferous Norway spruce (Picea abies), although uncertainty prevails about the water balance of such systems (Geßler et al. 2007). Conversely, mountainous forests are typically associated with moist climatic and edaphic site conditions. In humid regions, vegetation becomes a crucial hydrological link, however, between soils and atmosphere, so that high-altitude ecology becomes a key determinant in a changing environment of evapotranspiration and run-off, and as a consequence, of hazardous risks by erosion, landslides and flooding, altogether arising from the scope of site water balances. An exacerbating challenge for clarifying the linkage between water balance components 
is the high spatial heterogeneity of mountainous landscapes, which makes interdisciplinary cooperation mandatory between the research fields of landscape hydrology, tree ecophysiology, forest meteorology and mechanistic modelling.

The respective paper collection of this issue contributes to key aims pursued by research programs like the IGBP core project BAHC (Biospherical Aspects of the Hydrological Cycle) und GEWEX (Global Energy and Water Cycle Experiment) and arose from the interdisciplinary research cooperation on "Methods for Coupling Hydrological and Biological Processes at the Landscape Level" funded by Deutsche Forschungsgemeinschaft (DFG) as Be 1721/2 Hu 636/6 and Ma 1763/3 during 1998 through 2003. Key findings of this initiative addressed in this issue are briefly highlighted, as follows:

Matyssek et al. (2009) assessed tree transpiration and structural differentiation along with stand water balances of mono-specific and mixed forests at sub-alpine, mountainous and colline elevation. Consistencies rather than pronounced contrasts in tree-allometric structures of relevancy for water transport were encountered, irrespective of elevation and forest type. Transpiration depended on site conditions rather than site-dependent adaptation. At the mountainous site, stand canopy transpiration was low in proportion of the high seasonal precipitation, which mostly fed run-off from the site. The water balance of the subalpine site resembled, at lower precipitation, that of the mountainous site, whereas the budget was balanced during summer at colline elevation.

Hofmann et al. (2009) modelled soil patterns for the watershed of the Halbammer $\left(42 \mathrm{~km}^{2}\right)$ in the Bavarian Alps. The database consisted of 297 profiles taken during a one-month field survey in summer 2001 and the topographical and geological maps (1:25 000) of the area. Regionalization was based on the tree-based-CARTAlgorithm (Classification And Regression Trees, Breiman et al. 1984). The decision rules of these trees then served as basis for the derivation of soil maps that were created using the geographical information system ArcGIS 9.2. The accuracy of the regionalization was estimated using mathematical criteria as well as human expertise. Six to 10 units proved to be a good number concerning the available data, but even then not all of them could be separated by CART. The distributions of soil classes in the terminal nodes of the classification trees were useful for the interpretation of the soil units in the maps' legends and also helped to identify typical soil patterns in the study area.

Stumpp et al. (2009) evaluated two types of pedotransfer functions (PTF's) for their accuracy and applicability to a broad range of Alpine soils in the Halbammer area in southern Bavaria (Mishra and Parker 1989; Arya and Paris 1981; Schaap et al. 2001). The PTF's were evaluated by comparing predicted with measured water retention values. Additionally, a process-based functional validation was performed by simulating the water flow using the measured and predicted soil hydraulic data. They found that water contents in the middle suction range were underestimated in sandy soils and overestimated in soils with low bulk density. The functional evaluation showed improved model accuracy when the predicted saturated conductivity was adjusted to more realistic values from literature.

Engelhardt et al. (2009) present applications of information and complexity measures (Lange et al. 1997; Wolf 1999) to hydrological time series in two climatically different forest ecosystems in Southern Germany and Southern Ecuador. They hypothesize that complexity of hydraulic time series increases with the number of abiotic and biotic variables involved in the generating process of the time series. Hydrological time series cover the sequence of hydrological signals from open precipitation, throughfall, sapflow, water fluxes in the soil compartment and system discharge. They detected pronounced data aggregation and transformation effects of hydrological signals along their path through subsystems in terms of information propagation, but found similar temporal patterns for the ecosystems under study. As a result of intensive abiotic and biotic interactions, a pronounced maximum of complexity was found in the moisture signal of the soil compartment.

In general, soil landscape modelling can provide maps of soil functional groups. Unfortunately, misclassification rates are typically high and to date approaches to include small scale heterogeneity are missing. It is still an open question to which extent spatial heterogeneity has an impact on important soil functions like groundwater recharge, nutrient availability or landslide risks in forests under the specific mountainous conditions. Sensitivity to variability is a crucial point for hydrological landscape modelling. Use of simplified models and effective parameter estimates are common strategies but require rational criteria to ensure validity and transferability.

\section{References}

Arya LM, Paris JF (1981) A physicoempirical model to predict the soil moisture characteristics from particle-size distribution and bulk density data. Soil Sci Soc Am J 45:1023-1030

Breiman L, Friedman JH, Olshen RA (1984) Classification and regression trees. Wadsworth, California

Dertz W (1996) Buchenwälder im Zielkatalog der Forstwirtschaft. In: Buchenwälder - ihr Schutz und ihre Nutzung. Stiftung Wald in Not, Bonn, Germany, pp 2-8

Engelhardt S, Matyssek R, Huwe B (2009) Complexity and information propagation in hydrological time series of mountain forest catchments. Eur J Forest Res. doi:10.1007/s10342-009-0306-2 
Geßler A, Keitel C, Kreuzwieser J, Matyssek R, Seiler W, Rennenberg H (2007) Potential risks for European beech (Fagus sylvatica L.) in a changing climate. Trees 21:1-11

Hofmann M, Engelhardt S, Huwe B, Stumpp C (2009) Regionalizing soil properties in a catchment of the Bavarian Alps. Eur J Forest Res. doi:10.1007/s10342-008-0242-6

Körner CH (2003) Alpine plant life: functional plant ecology of Hogh mountain ecosystems. Springer, Berlin, p 344

Köstner B (2001) Evaporation and transpiration from forests in Central Europe: relevance of patch-level studies for spatial scaling. Meteorol Atmos Phys 76:69-82

Köstner B, Falge EM, Alsheimer M, Geyer R, Tenhunen JD (1998) Estimating tree canopy water use via xylem sapflow in an old Norway spruce forest and a comparison with simulation-based canopy transpiration estimates. Ann Sci For 55:125-139

Lange H, Hauhs M, Rohman C (1997) Classification of terrestrial ecosystems with complexity measures. In: Schweitzer F (ed) Self-organization of of complex structures: from individual to collective dynamics. Gordon and Breach, London, pp 293-306
Matyssek R, Wieser G, Patzner K, Blaschke H, Haeberie K-H (2009) Transpiration of forest trees and stands at different altitude: consistencies rather than contrasts? Eur J Forest Res. doi: $10.1007 /$ s $10342 \neg 008-0243-5$

Mishra S, Parker JC (1989) A user's guide to SOILPROP. Report 8801. Environmental Systems and Technology, Blacksburg, Virginia

Schaap MG, Leij FJ, van Genuchten MT (2001) Rosetta: a computer program for estimating soil hydraulic parameters with hierarchical pedotransfer functions. J Hydrol 251:163-176

Stumpp C, Engelhardt S, Hofmann M, Huwe B (2009) Evaluation of pedotransfer functions for estimating soil hydraulic properties of prevalent soils in a catchment of the Bavarian Alps. Eur J Forest Res. doi: 10.1007/s10342-008-0241-7

Wieser G, Tausz M (eds) (2007) Trees at their upper limit - treelife limitation at the alpine timberline. Springer, Plant Ecophysiology, vol 5, p 232

Wolf F (1999) Berechnung von Information und Komplexität in Zeitreihen. Bayreuther Forum Ökologie (bfö) 65:163 